\title{
Direito à identidade: itinerários de um paradoxo
}

\section{Identity right: itineraries of a paradox ${ }^{*}$}

\author{
Doglas Cesar Lucas
}

\section{Resumo}

O presente texto pretende demonstrar que a identidade tem se transformado numa categoria essencial para se compreender os conflitos contemporâneos. Diferentemente de suas formas tradicionais de identificação, a identidade tem se estratificado, tornado-se múltipla, reclamando reconhecimento jurídico para as suas diferentes formas de produção de pertença. Partindo dessa premissa, objetiva-se demonstrar que, apropriada pelo direito, a identidade é reduzida a um modo de identificação, uma vez que o direito a constitui normativamente, descaracterizando-a. O trabalho foi desenvolvido por meio de revisão bibliográfica de caráter descritivo e crítico, notadamente vinculado aos estudos de filosofia e filosofia do direito.

Palavras-chave: Identidade. Pertença. Reconhecimento. Direito à identidade.

\section{Abstract}

This paper aims to show that identity changed to an essential category for the understanding of contemporary conflicts. Different from its traditional forms of identification, identity became stratified, becomes multiple, and claims for juridical recognition for its various forms of appurtenance production. Proceeding from this assumption, we aim to demonstrate that, when appropriated by law,

Texto produzido a partir do projeto de pesquisa intitulado "Direitos Humanos, Identidade e Mediação", coordenado pelo autor e financiado pelo edital Universal 14/2011 do CNPq, processo $n^{\circ} 481512 / 2011-0$, vinculado ao Mestrado em Direito da Universidade Regional do Noroeste do Estado do Rio Grande do Sul - UNIJUI.

* Pós-doutor em Direito pela Università degli Studi di Roma Tre, Itália. Doutor em Direito pela UNISINOS e mestre em Direito pela UFSC. Professor nos cursos de Graduação e Mestrado em Direito da UNIJUÍ. Professor no Curso de Graduação em Direito do Instituto Cenecista de Ensino Superior de Santo Ângelo - IESA. Pesquisador do CNPQ. Avaliador do MEC/INEP. Ijuí - RS Brasil. E-mail: doglasl@unijui.edu.br 
identity becomes reduced to an identification mode since law, in terms of norms, constitutes identity by disfiguring it. This study was worked out reviewing descriptive and critical bibliography, notably the one associated to the study of Philosophy and Legal Philosophy.

Keywords: Identity. Belonging. Recognition. Identity right.

\section{Introdução}

A identidade tem se transformado numa categoria central nas discussões políticas e teóricas do nosso tempo. O avanço da imigração, os conflitos religiosos, as demandas étnicas e nacionalistas, a nova gramática do corpo e suas múltiplas manifestações de natureza sexual, de gênero e de cor têm provocado um intenso movimento de afirmação e reconhecimento daquilo que se é em contraposição àquilo que se diferencia. Ampliam-se e se complexificam os códigos de identificação/ identidade que reclamam ser lidos e reconhecidos pelos diferentes sistemas, entre eles, o direito. Parece que não se pode acessar ao mundo sem recorrer a uma identidade, destaca Remotti (2010). Ela sugere ser, no contexto contemporâneo de inseguranças, uma ilha de proteção, uma promessa de certeza e estabilidade.

Para isso, a identidade depende de certa obsessão metafísica, de uma ligação abstrata a algo que, para além das particularidades, garanta a persecução de um projeto compartilhado. É como se somente na unidade dessa representação as particularidades adquirissem sentido. Mas esse apelo ao semelhante, ao igual, esconde um jogo ambivalente com o seu oposto, com a sua diferença, que é condição de possibilidade para a identidade. Definitivamente, a identidade só é um evento possível na paradoxal relação com o outro, com o estranho, com a sua diferença (RESTA, 2011). A criação das condições de igualdade dentro da comunidade são, também, as condições de diferença para fora dela. A amizade entre iguais, nesse sentido, pressupõe uma desconfiança entre os diferentes. Os de dentro e os de fora se institucionalizam. Para se incluir os primeiros, faz-se necessário excluir os segundos. 
Nesse jogo de ambivalências e obsessão, a identidade transparece sua face velada e perigosa. Funciona como mito, como promessa nem sempre realizável. Transforma ilusão e aspiração em realidade (BAYART, 1996). Separa para unir. Inventa ligações artificiais que impedem o reconhecimento dos traços de humanidade comum em cada particularidade, alimentando diferenças excludentes. Por isso, quem se coloca contra nossa identidade parece se transformar em nosso inimigo. O "nós" identitário, ao se contrapor ao "outro" e à sua diferença, constrói os limites do "nosso" e do seu entorno. Sua estabilidade cobra o preço da instabilidade e a sua continuidade, o da descontinuidade. A identidade é um ser que é em si e que também o é por não ser outra coisa. A negação de seu oposto é a condição de sua unidade. Enfim, toda identidade tem "como margem um excesso", tem sempre um algo mais (HALL, 2003).

Este texto pretende demonstrar que a identidade, diferentemente de suas formas tradicionais de identificação, tem se estratificado, tornadose múltipla, reclamando reconhecimento jurídico para as suas diferentes formas de produção de pertença. O processo de fragmentação das identidades produz uma espécie de subjetividade flexível, decorrente da vivência entrelaçada de diferentes culturas dentro de um mesmo indivíduo, que, na composição de sua vida, transita por uma diversidade de grupos sociais com práticas diferenciadas e até divergentes. A essência identitária desmoronou e, em seu lugar, muitas identidades cambiantes e diversas convivem em um mesmo espaço, em espaços diferentes, produzindo estranhamento e reafirmando suas unidades.

Para enfrentar esse propósito, o trabalho foi dividido em vários momentos. A primeira parte é dedicada a demonstrar que a identidade é um evento essencialmente moderno e de existência precária nas sociedades de tipo comunitarista, como as pré-modernas. A segunda etapa do artigo enfrenta a identidade como fenômeno paradoxal, que depende de seu externo e que se alimenta de sua diferença. Nessa mesma direção, na terceira etapa, defende-se a ideia de que o mundo contemporâneo vive uma explosão de demandas identitárias, cada uma delas desejando reconhecimento e proteção do direito. Por fim, em fase de conclusão, aduz-se que o direito à identidade de tipo estratificado 
alimenta um jogo interminável de identidades que se rivalizam e que se negam, cada uma delas reproduzindo o próprio estatuto

\section{O ser como um traço da identidade nas sociedades pré- modernas}

A identidade nasceu, segundo Resta (1997), para indicar uma semelhança, para destacar aquelas características específicas a serem replicadas. Estava associada à ideia de essência, à possibilidade de uma representação pura de mais do mesmo. Era tida como algo em si, como aquilo que não mudava com o tempo e que, por isso, estava para além da história, para além da tradição, fora da interferência humana. 0 "ser é", proferiu Parmênides (1996, p. 118), simplesmente. Ao contrário do mobilismo de Heráclito, que defendia uma natureza mutável do ser (pois o "Ser-é" e "Não-é" ao mesmo tempo; é cheio e vazio), Parmênides sustentava a tese de que o ser em si é imóvel, tem uma essência e uma permanência imutável, sendo o movimento apenas uma falsa percepção dos sentidos humanos. Nesse sentido, idêntico é aquilo que não se altera, que permanece igual, apesar das mudanças de sua totalidade. A identidade é um a priori; não é alcançada pelo tempo e tem uma essência em si. "Parménides dijo que el ser tiene su lugar en una identidad” (HEIDEGGER, 1990, p. 69). O ser, nesse caso, é um rasgo da própria identidade, destaca Heidegger. Ela é uma manifestação interna, enquanto a alteridade é externa. A identidade se confunde com a própria substância que não se altera no tempo e no espaço. Sua máxima é, pois, formulada da seguinte forma: $A=A$ e $A \neq$ não - $A$, na qual se percebe $a$ notória exclusão da alteridade. O outro não faz parte do ser e a diferença (alteridade) não está contida na ideia de identidade.

Ao sustentar uma ordem cósmica imutável e a absoluta verdade do mundo das ideias em contraposição às imperfeições do mundo sensível, Platão reproduz teoricamente a imutabilidade do ser. A grande preocupação do filósofo é a busca pela verdade. Para ele, o saber absoluto somente pode estar presente nas ideias e jamais no mundo sensível. Ideia representa uma essência, significa a coisa mesma em 
sua dimensão mais autêntica; carrega um conceito universal, uma base a priori (transcendental/divina, que reside na alma, a qual faz a mediação com o mundo sensível), é o fundamento do ser e a finalidade que aparece como um bem, como um valor (HIRSCHBERGER, 1995). A percepção alcançada pelos sentidos é insegura, uma vez que é sempre mutável. Assim, por exemplo, na visão platônica, um Estado bem ordenado e justo é aquele no qual as pessoas não fazem o que querem, mas o que devem fazer segundo sua finalidade, assumindo sua função específica dentro da totalidade. Essa é a norma de justiça: harmonizar as diferenças numa unidade, seja ela o indivíduo ou a cidade. Nessa ordem das coisas, cada um ocupa o seu lugar de acordo com suas habilidades naturais, sendo a individualidade algo inexistente. A identidade, pois, não é representada ou questionada como um atributo da consciência reflexiva, sugerindo apenas uma espécie de repetição de uma posição no mundo de acordo com determinada preparação e capacidades em uma sociedade bem ordenada.

Aristóteles, por sua vez, tratou da identidade em termos lógicos. Para o filósofo de Estagira, a identidade é uma relação entre substâncias iguais, entre elementos que apresentam a mesma característica, independentemente da coisa em que tais substâncias se encontrem. Não interessa a coisa em si, a sua diferença, mas as substâncias que conformam o ser em sua generalidade ou especificidade. Quando refere que a identidade é a igualdade entre as mesmas substâncias presentes em coisas diferentes, está anunciando uma relação de igualdade entre as especificidades que as diferem do gênero. A diferença específica do ser está na substância, e não na coisa em si. Assim, apenas indiretamente a diferença importa ao conceito de identidade por ele trabalhado, sobretudo porque a identidade é em si mesma e negação em relação àquilo que não é (HÖFFE, 2008).

Aplicada aos seres humanos, a ontologia das essências propugna uma espécie de singularidade essencial de cada ser humano e uma pertença também essencial que não depende do tempo e dos acontecimentos históricos. É um atributo herdado desde o nascimento ou desenvolvido como uma habilidade que manifesta a sua condição 
inevitável (DUBAR, 2007). Nesse sentido, o ser é, em si, o resultado das inscrições naturais que definem sua posição no mundo, seus atributos, sua classe social e sua finalidade. Não se pode dizer, nesse caso, que a identidade pressuponha ou esteja baseada na ideia de reconhecimento mútuo. Tudo se limita ao papel desempenhado pela experiência coletiva, comunitária e pelos simbolismos pré-programados. A consciência reflexiva de si mesmo, ao menos como a conhecemos desde a modernidade, é ignorada (RICOEUR, 2006). A identidade tem uma força replicadora na sociedade pré-moderna. Sua missão se realiza na tarefa de identificar-se com o mesmo, sem recorrer a um mecanismo próprio de diferenciação e identificação.

Sem um ambiente que prestigiasse a subjetividade e a individualidade como vetores determinantes do ser, a identidade não tinha como assumir traços de diferenciação. A identidade como autoconsciência é um acontecimento moderno. Antes, ela se caracterizava como uma forma totalizante e natural de ligar o homem a lugares pré-determinados. No mundo antigo, essa relação de identidade interna é uma decorrência da própria condição da vida feliz no interior da pólis. O indivíduo depende da organização coletiva para existir. Ele não se individualiza. Ele é, em si mesmo, parte da cidade, uma vez que não é possível viver fora dela. Não se pode prescindir da vida comunitária como espaço natural de sobrevivência individual. O indivíduo não é em sua particularidade. Ele somente é numa relação com o todo. Nesse período, descreve Elias (1994, p. 131), "o fato de pertencer a uma família, tribo ou Estado desempenhava um papel inalienável na imagem do homem". Não se conhece, nesse paradigma identitário, uma identidade de tipo funcional. A identidade antiga era garantida por uma espécie de continuidade. Ela reproduzia mais do mesmo sem ter que apelar para o diferente. Tem uma essência, por isso não tem necessidade do jogo ambivalente com seu oposto. As alianças e as lealdades são naturais e condição de possibilidade da vida individual na pólis. Nesse tempo, operam-se laços que desconhecem riscos, pois as expectativas são estáveis e sustentadas em crenças. Não há um jogo de diferenças que possa ser alimentado. O sujeito é a encarnação da própria cidade. Fora dela, ele não existe. 
Comparado à modernidade, o distanciamento espaço-tempo no qual se desenvolvem as relações identitárias pré-modernas é bastante baixo, praticamente reduzido às circunstâncias do local, da cidade, da família etc. Por isso, as relações de parentesco, os vínculos com a comunidade local, as cosmologias religiosas e a tradição (uma forma de orientar o presente e o futuro a partir do passado) são, segundo Giddens (2002), os ambientes de promoção da confiança localizada. O tempo e o espaço se conjugam na situacionalidade do lugar.

\section{Modernidade e identidade como consciência de si}

O reconhecimento do indivíduo isoladamente considerado e sua proteção contra as intervenções arbitrárias do Estado é um traço marcante do estatuto político e jurídico da modernidade. A ideia de que o indivíduo é portador de direitos que lhe são inerentes é determinante no surgimento do Estado moderno. Como se sabe, as teses contratualistas, em todas as suas versões, sustentavam que o homem é titular de direitos naturais, os quais devem ser protegidos pelo Estado que o próprio homem faz nascer mediante o contrato social. O indivíduo é o fundamento e o limite do poder. Ao contrário de Aristóteles, para quem o indivíduo dependia da existência do Estado como acontecimento natural anterior a ele, a modernidade coloca nas mãos do indivíduo o rumo de sua história. É ele quem faz nascer o Estado e é ele quem define os limites de sua autoridade. É a sua existência individual (sua liberdade, sua propriedade, sua vida) que deverá estabelecer a forma e os conteúdos da atuação estatal e fundamentar o seu poder de ação. O indivíduo atinge a maioridade e não precisa mais obedecer à lei do outro, mas à própria lei, dirá Kant.

Pode-se dizer que, a partir de Locke, o paradigma moderno da identidade mereceu um tratamento mais substancial. Em sua obra Ensaios acerca do entendimento humano (2000), o filósofo inglês refere que o "eu" não é feito de uma substância imutável que permanece inalterada com o tempo e que impede a identidade pessoal de modificarse. A identidade não é resultante de um atributo essencial, mas é 
compreendida como produto da consciência. Enquanto substância, o ser humano se modifica o tempo todo. O que se mantém idêntico com o passar do tempo é a sua consciência. A identidade do homem se constitui pela relação constante entre sua substância e sua consciência. Por isso, o ser que ele realmente é, enquanto substância, não é a mesma coisa que aquilo que o homem representa para sua consciência. Esta liga e aproxima a realidade cambiável do homem com sua compreensão de si mesmo, superando a heterogeneidade e a multiplicidade da existência e ações que constituem o indivíduo. Sua identidade é, pois, a forma como o sujeito autoconsciente se percebe, independentemente das variações objetivas que assolam a sua existência enquanto sujeito histórico, enquanto uma unidade de fato. Não decorre de sua substancialidade, que muda e se altera o tempo todo. Trata-se de um produto da consciência, uma construção que atribui sentido e unifica a multiplicidade de eventos que o fazem ser o que é. "Perduto il suo atributo di identità, la sostanza di cui è fato l'io si frammenta in modo enevitabile. Essa perde la sua unità e permanenza:l'io in definitiva non è più una sostanza" (REMOTTI, 2010, p. 57) $)^{1}$.

Não se tratando de uma substância perene, de uma manifestação de uma natureza essencial, a identidade assume uma dimensão variável e o "eu" é capaz de mudar e ganhar novos contornos, independentemente de elementos formais que o alcançam, pois é na consciência que se processam as modificações que realmente importam para o indivíduo compreender-se como é. A identidade, para Locke, varia de acordo com a extensão da consciência. Se ela muda com o tempo, por certo que também mudará a identidade e a forma como o ser compreende sua relação com o mundo objetivo. A identidade, portanto, como derivação da consciência, não é absoluta. Modifica-se, é efêmera e precária, dirá Remotti (2010).

Tradução livre realizada pelo autor: "Perdido o seu atributo de identidade, a substância da qual é feito o "eu" se fragmenta de modo inevitável. Ele perde a sua unidade e permanência: o "eu" definitivamente não é mais uma substância." 
Sem recorrer a detalhes mais profundos do debate oitocentista, interessa destacar em nosso trabalho que somente com o aparecimento da ideia de um sujeito como ser autoconsciente de sua condição de temporalidade foi possível desencadear-se o paradigma moderno da identidade. A invariabilidade e substancialidade absoluta definitivamente não são mais elementos da condição identitária. O ser se altera, compreende-se e se questiona ontologicamente. O que é invariável no ser? Podemos afirmar a identidade do indivíduo como aquilo que não se altera no tempo, como aquilo que permanece idêntico, mesmo com o passar dos anos? É possível o ser manter sua identidade estática, mesmo mudando sua substância? Se essas perguntas, na Antiguidade, tinham feito ecoar respostas enfáticas a favor de uma identidade substancial do ser, sustentadas em sua imutabilidade e constância, com a modernidade, essa constatação é substituída pela ideia de identidade como processo, como invenção, como ficção, como resultado da consciência.

Livra-se a identidade do conceito de essência, mas incorpora a dimensão da temporalidade. É elaboração permanente que se alimenta de diferenciações e ambivalências. Seu paradoxo é a sua condição de possibilidade. Existem identidades porque não é possível uma identidade absoluta. Cada uma delas vive da negação de sua diferença. Aidentidade do ser é um traço de sua presença diferente, uma característica que o diferencia da diferença do outro. É na relação com seu oposto que a identidade afirma seu estatuto. É o que é por não ser outra coisa. Seu espaço e seu tempo são colonizados de vez pela lógica da diferenciação e da identificação. A identidade, pois, a partir da modernidade, sobretudo contemporaneamente, identifica ao diferenciar, reproduz unidade por processos de separação, unifica dividindo e inclui excluindo. $E$ tudo isso é resultante de processos complexos que dão facticidade e realidade objetiva àquilo que o indivíduo acredita ser sua condição. Ou seja, se, no modelo pré-moderno, o ser, como dizia Heidegger (1990), era um rasgo da própria identidade, com a modernidade. a identidade passa a ser um rasgo do ser. 


\section{A identidade como resultado de um processo de enfrentamento e reconciliação}

Se a filosofia clássica, de inspiração aristotélica, reconhecia a identidade apartada da alteridade, como uma substância invariável no tempo e concebida a partir de seu interno, sem relação com o exterior, no início do século XIX, Hegel fez uma profunda revisão na relação entre identidade e alteridade. Ele não separou o reconhecimento da autonomia, tampouco a universalidade da particularidade. Aponta claramente que a identidade surge de uma relação universal entre particularidades autônomas que se reconhecem mutuamente. A união entre os indivíduos não apenas pressupõe autonomia, segundo Hegel, mas a cultiva, pois ela permite aos indivíduos recuperarem sua identidade e aprenderem algo mais sobre a própria diferença com os outros. Por isso, afirma Hegel (1995), para o indivíduo, o reconhecimento significa um saber afirmativo de si mesmo em outro si mesmo.

Na dialética da diferencialidade de Hegel, cabalmente divergente de Parmênides, a identidade e a diferença são coexistenciais, compenetradas. Elas se implicam mutuamente. As coisas são contraditórias e determinantes na definição de todo e qualquer conceito. A contradição é a raiz do movimento e da vitalidade das coisas. Assim, também a identidade tem uma relação simbiótica e constitutiva com seu oposto. A alteridade é parte integrante do conceito de identidade e viceversa; ela "si insinua nell'identità e ne diviene una dimensione sostanziale, fondamentale, irrinunciabile" (REMOTTI, 2010, p. 27) ${ }^{2}$. Desse modo, o outro, diferente, assume uma posição importante na definição do sujeito como tal. Essa abertura em direção ao outro superou definitivamente a ideia de identidade como uma essência, como mais do mesmo.

A identidade de tipo puramente abstrato é representativa, refere Hegel, de um imobilismo intelectual que é invenção, falsificação e mito.

Tradução livre realizada pelo autor: "se insinua na identidade e se transforma numa dimensão substancial, fundamental e irrenunciável.” 
A identidade é uma construção permanente, o resultado de um processo histórico que não se esgota jamais, mas que, por outro lado, consegue produzir uma unidade no meio da tanta multiplicidade e transformação. A unidade da identidade se apoia na ideia de uma universalidade que se contrapõe aos localismos e interesses particulares. De acordo com Emanuele Lago, em seu estudo sobre Hegel e Heidegger,

l'identità è tale solo perché è differenza e la differenza è tale solo perché è identità. Ognuno dei due momenti contiene l'altro, ma allo stesso lo respinge da sé, dal momento che l'identità che è differenza è la negazione dela differenza e che la differenza che è identità è la negazione dell'identità (LAGO, 2008, p.133). ${ }^{3}$

Definitivamente, Hegel introduz a diferença como condição de possibilidade da própria ideia de identidade.

Seja no âmbito da identidade cultural ou individual, o contato com o outro, com o diferente, tende a reforçar e confirmar a ideia de "nosso". As trocas que se operam na lógica da alteridade acabam por interferir na programação interna da identidade, o que altera os confins do próprio entorno e, com isso, os níveis da própria particularidade. O ser é afetado pelo outro em sua condição de ser. Esse contato de alteridade marca as diferenças irredutíveis existentes entre duas pessoas ou culturas, recriando as distâncias entre elas. Nesse movimento, a alteridade funciona como uma forma de certificação da identidade, pois confirma e reforça sua unidade inegociável.

Um modelo rígido de identidade, que compreende a formação do "nós" como um movimento exclusivo e não interativo, sofre de uma miopia epistemológica. É nesse sentido que Remotti destaca que, para compreender a identidade, é necessário mover-se contra ela. Pois a identidade nos cega, impede-nos de ver os acessos que ela mesma

3 Tradução livre realizada pelo autor: "a identidade é tal só porque é diferença e a diferença é tal somente porque é identidade. Cada um dos dois momentos contém o outro, ao mesmo tempo em que se autorrejeitam, momento em que a identidade que é diferença é a negociação da diferença e que a diferença que é identidade é a negociação da identidade." 
percorre ao se constituir. A exasperada exigência de identidade parece mascarar a sua história e revelar somente o resultado final de suas escolhas, escondendo sempre o processo de constituição.

Em Heidegger (1990), a unidade da identidade é apresentada como um elemento fundamental da definição do ser. O ser fala por intermédio da identidade, reside nela. De acordo com o filósofo alemão, a conhecida proposição de identidade $A=A$ encerra um fechamento que se basta no próprio objeto referenciado e não dá conta da identidade como um traço constitutivo do ser. Quando se diz que "A" é igual a "A", dissemos que o A se basta em si mesmo, que não necessita de qualquer relação de comparação com outra unidade qualquer. A fórmula $A=A$, portanto, manifesta o princípio da igualdade, pelo qual um " $A$ " é suficiente para expressar a sua fórmula de identidade. Ou seja, ele é autoevidente. Não há demonstração lógica dessa auto-evidência, mas tão somente da impossibilidade de sua contradição.

Ao se constituir como um rastro do ser, a identidade se revela como historicidade presente no ser, como realidade que se transforma em compreensão de uma dada posição do ser no mundo. As ligações com a tradição, com o mundo que previamente se apresenta a ele e as conexões intersubjetivas baseadas em saberes consolidados antes da presença objetiva do homem no mundo da vida auxiliam na capacidade de o homem compreender como ser individual e coletivo, como ser pertencente a um tempo de continuidades perenes que compõem a noção de identidade. O outro, semelhante ou diferente, é condição indispensável para o ser compreender-se como é, para situar-se no mundo, para tornar possíveis os olhares que desvelam o estranho e ajudam a dar sentido à pluralidade de horizontes empíricos (GADAMER, 2005). Essa conexão com o outro, no entanto, não é lógica, mas ética; reclama uma solidariedade autêntica, uma convivência que é capaz de nos corrigir ou nos confirmar. Enfim, o outro define nosso limite, o nós, o alcance das diferenças e das igualdades, define a cultura e a identidade como sua visão das coisas em perspectiva.

O outro, portanto, é a pré-condição ética da identidade. O "eu' decorre de sua implicação prévia com os outros. Os outros não são 
aqueles diferentes de mim, pronuncia Heidegger (2002), mas aqueles entre os quais também se está. Essa leitura fenomenológica do "eu" e do "outro" foi fundamental para denunciar os traços excessivamente metafísicos que ofuscaram a presença da singularidade e da unicidade do "outro" como diferente e como parte de mim mesmo, ou seja, para denunciar uma espécie de transformação "do outro no mesmo" que nada mais representa que o próprio banimento do "outro". Afinal, o outro é sempre singular, pessoa única, com história particular, lugar, tempo, gênero, desejos e necessidades (DOUZINAS, 2009).

\section{0 mesmo e o outro}

Cinco grandes movimentos de aproximação ao mecanismo da identidade podem ser percebidos na reconstrução histórico-filosófica dessa categoria, ensina Resta (2011). O primeiro, já apontado, indica uma indissociável ligação ambivalente entre a identidade e a diferença. Como se disse, a diferença é a condição da identidade e vice-versa. O segundo refere que não se trata de uma relação de ambivalência com qualquer diferença. A identidade escolha a sua diferença, ela define a programação do seu código. Por isso, pode oscilar, mudar, transformar-se, mas continua comunicando uma identidade. O terceiro movimento de aproximação consiste em tratar a identidade, em um só tempo, como recipiente e conteúdo, pois a sua definição considera tantos os seus elementos constituidores quanto a sua forma e estrutura de apresentação. Essa é uma questão determinante no cenário de identificação contemporâneo. Um mesmo sujeito pode, portanto, carregar múltiplas narrativas de identidade sem mudar o que ele é enquanto ente objetivo. Fala de si a identidade, mais para si mesma do que para fora. Promove um encontro constante e complexo consigo mesma na medida em que reafirma a própria contingência. Por isso, um quarto momento de aproximação pondera que a identidade não pode ser confundida com um sentido vindo de fora, imposto pelo seu exterior. Não pode, aduz Resta (2011, p. 10), ser reduzida a uma máscara; requer autenticidade "di un mondo privato perché segreto, difficilmente 
sbandierabile ai quattro venti" ${ }^{\text {. }}$. O último movimento apontado pelo autor reconhece que a identidade não tem um eu absoluto e soberano. Por isso mesmo, o eu fragmentado e atomizado tenta ocupar todos os espaços de emancipação, como forma de escamotear a sua contingência presente em seu ser. Uma forma de fazer isso é transferir sua contingência da biologia para a biografia, dando formatos e opções diversas de representação do eu.

A identidade configura um espaço que é seu. Delimita o externo e diminui as contingências nesse universo de muitos acessos. Garante um lugar de pertença ao mesmo tempo em que constitui o próprio lugar. O sujeito pode percorrer vários ambientes ao mesmo tempo, mas o faz a partir de um lugar. Dele sai, para ele volta. A partir dele, fala e escuta. A identidade desse lugar é o próprio espaço da identidade. É o lugar da estabilidade instável, da negociação permanente com o externo. É o ambiente que organiza e ordena, que negocia com múltiplos espaços ao mesmo tempo, que conecta e unifica as semelhanças que habitam diferentes lugares. Com isso, reduz a complexidade pela diferenciação, pela conexão das particularidades em uma unidade, num espaço e num tempo só seu. Ao fazer isso, castra, corta, perde, reduz acesso de pertença múltipla. Por outro lado, organiza, define, ordena, transforma contingência em algo que pode ser apropriado, compartilhado e reproduzido. Tanto mais rica é uma cultura quanto mais espaços ela consegue mediar na elaboração de sua história.

Ao ser construção, invenção, a identidade é também uma convenção, uma escolha e uma decisão entre tantas possíveis. Não que esse processo de decisão seja totalmente livre de interferências e realizado com plena clareza. Nascemos em uma cultura e aceitamos os contornos que ela nos fornece. De qualquer modo, seja responsabilidade individual, seja coletiva, a identidade é uma opção, uma construção que põe determinados limites e não outros. E tais limites não são estáticos.

Tradução livre realizada pelo autor: "de um mundo privado porque secreto, dificilmente espalhado aos quatro ventos." 
Podem ser alterados, modificados, reconstruídos. Nisso reside a decidibilidade da identidade, que não é uma essência impositiva sobre o ser, mas uma forma particular de sua representação, que sofrerá sempre com a dinâmica da própria existência. Quando decidimos, separamos. A decisão pressupõe uma escolha e vice-versa. Para garantir a sua particularidade, a identidade precisa decidir sobre o seu oposto, excluindo-o e definindo o seu externo (REMOTTI, 2007).

Existe um percurso oscilante da identidade. As identidades mudam, transformam-se, deixam de ser para continuarem sendo. Sua descontinuidade cambiante é sua força e sua persistência de continuidade. Assim, garante estabilidade, transcende o tempo presente e se coloca numa condição de intertemporalidade. Reapropria-se do próprio passado, reelaborando-o. Transita por lugares e tempos distintos. Portanto, anota Resta (1997, p. 63), "l'identità si oculta e si nasconde, simula e dissimula, si riunchiude nel segreto per reapparire dopo in qualche altro luogo e in qualche altra forma. E errante e nello stesso tempo stabile, nômade e stanziale; si può osservare e non si pò osservare: oscila." 5

A ambivalência paradoxal que constitui a identidade não é, porém, um jogo simples entre seus códigos binários. Fato interno e externo se delimitam mutuamente; um é condição objetiva do outro. Mas não é só isso. O interior da identidade se auto-observa a partir das diversas possibilidades de intermediação e diálogo com seu exterior. São vários os pontos de encontro e desencontro. Diferentes tempos de mundo, representantes de uma multiplicidade de entornos, de outras identidades são contrapostos e observados a partir do interior. Uma identidade cultural convive com várias outras identidades que fazem parte de seu entorno complexo e que exigem estratégias de seleção advindas do interior para que a oposição a cada uma das identidades opostas

Tradução livre realizada pelo autor: "a identidade se oculta e se esconde, simula e dissimula, reorganiza-se secretamente para reaparecer em qualquer outro lugar e de qualquer outra forma. É errante e ao mesmo tempo estável, nômade e permanente; pode-se observar e não se pode observar: oscila." 
seja separada, assimilada ou refutada. Um jogo infinito de contingência acompanhará a identidade. Ordena seu interior e seu exterior sempre pela via da redução de contingência, que inclui excluindo, que define um dentro e um fora e que une separando.

\section{Globalizações e o florescimento de identidades desconectadas: o sujeito descomprometido e estratificado}

A igualdade nacional, como se sabe, fortemente homogeneizadora e ao mesmo tempo negadora das diferenças, coexistiu com o individualismo e a afirmação do "eu" como sujeito em si mesmo, resultado dos contornos impessoais que a vida moderna passou a permitir e a considerar. De fato, a modernidade liberal é, nesse sentido, um momento paradoxal. Ao mesmo tempo em que prescreve a igualdade de todos perante a lei e institui um Estado legitimado pela convenção entre iguais, cria as condições para o florescimento de um ethos individual centrado na liberdade e na autonomia do sujeito, condição que ecoa nas diversas demandas de cunho individualista que o período vê eclodir e notadamente caracterizam o espaço de pertencimento como uma invenção da igualdade num ambiente de severas diferenças em conflito, sejam elas externas ou internas ao espaço estatal.

O acirramento desse processo torna o indivíduo, sem perder seu privilegiado vínculo nacional, uma biografia mais complexa, pois sua lealdade estatal, sustentada na sua pertença espacial e temporal, evidencia a universalidade de sua igualdade, enquanto sua liberdade permite refundar, todo tempo, novas lealdades com o seu eu-semelhante (seja no campo econômico, religioso, cultural, étnico etc.) e expor suas diferenças. Afirma sua etnia, sua cor, sua religião, sua sexualidade, seu gênero etc., bem como reconhece as diferenças materiais entre sujeitos de um mesmo Estado como algo próprio da liberdade em movimento. Iguais perante a lei, diferentes enquanto sujeitos históricos, os sujeitos veem as diferenças se aguçarem, notadamente no campo econômico, com o desenvolvimento da matriz produtiva capitalista e o avanço substancial das democracias constitucionais que deram visibilidade 
a uma nova agenda de demandas coletivas de cunho identitário, centradas, contudo, numa espécie de enraizamento do coletivo no individual (FERRY, 2010).

Isso não quer dizer que as formas de identidade-nós, de cunho comunitarista, tenham desaparecido com a modernidade e a globalização. O que se percebe é um movimento razoavelmente complexo, no qual a identidade-nós, tão cara às sociedades mais simples e à organização dos mundos antigo e medieval, começou a se transpor para uma identidadeeu. Com o avanço da agenda moderna e a conformação de um marco globalizante, notadamente nas áreas tecnológica, ambiental, econômica e comunicacional, a identidade-eu passou a ter um enorme significado na condução dos projetos pessoais e na pauta de satisfações, desejos e insegurança dos indivíduos, que não se encontram mais vinculados às modalidades tradicionais de identidade (GIDDENS, 2002). Aos poucos, o sujeito ganhou autonomia e se lançou em uma aventura centrada na liberdade, tendo que conviver com grandes doses de incerteza e insegurança, as quais, no contexto das comunidades tradicionais, eram praticamente desconhecidas. Bauman (2010) diz que a modernidade sólida foi substituída por uma modernidade liquefeita, um estado de coisas em que a insegurança dos projetos individuais agoniza o sujeito, o qual não encontra mais uma comunidade reprodutora de tradições compartilhadas coletivamente para restaurar a estabilidade.

A importância do papel da cultura, de certas práticas e costumes sociais locais na definição da identidade, entretanto, não representa necessariamente uma contradição em relação ao processo de generalização e unificação das instituições, dos símbolos e dos modos de vida perpetrados pela globalização, mas, paradoxalmente, parece apontar para a ocorrência de uma resposta reativa do particular às indiferenças alimentadas pelos mecanismos de padronização que afetam mundialmente quase todos os espaços de produção da vida social. Os novos reclamos por identidade e diferença, segundo Marramao (2003, p. 40), refletem uma reação aos efeitos de uma globalização que uniformiza, mas não universaliza, que comprime mas não unifica, “una mutua implicazione di 'omogeneizzazione' ed 
'eterogeneizazzione'. Un'inclusione della 'località' della differenza nella

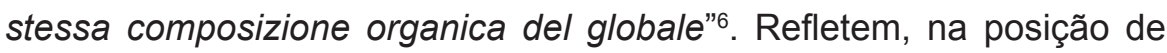
Bauman (2005), uma defesa-resposta contra um fenômeno que tende a desenraizar os vínculos identitários, tornando-os efêmeros, provisórios, sem continuidade, promovendo, por conta disso, o fortalecimento ou mesmo o retorno da ideia de comunidade e de suas formas de lealdade e pertença para com os semelhantes, uma maneira encontrada para se conquistar mais segurança e igualdade num mosaico de indistinções que parece desfavorecer as aproximações humanas mais duradouras.

Em decorrência da fragilização das formas tradicionais de se estabelecer vínculos comuns de lealdade, resultado de um mundo em mudanças contínuas, de transitoriedade permanente, os sujeitos tendem a ser seduzidos pelo discurso bastante tentador de retorno à "comunidade", uma forma de buscar segurança em um contexto de incertezas. A comunidade é requisitada como um abrigo contra as incertezas globais, uma condição para que os projetos de vida possam ganhar sentido no entendimento compartilhado. Os reclamos por identidade aparecem, então, como uma resposta à insegurança, uma tentativa de se estabelecer lealdades entre semelhantes em uma sociedade de sujeitos desenraizados, na qual os laços comunitários tradicionais são cada vez menos perenes.

Ocorre, no entanto, que nem mesmo a comunidade tem conseguido desempenhar habilmente esse papel (quando não o dificulta ainda mais), pois a forma como o mundo estimula a realização de projetos seguros de vida, sempre como um desafio individualizado, parece não ser a receita mais adequada para alcançar tais objetivos, o que tende a aumentar ainda mais a insegurança. Além disso, a estratégia de fechamento das comunidades em torno de si mesmas tem acirrado a guerra do "nós" contra o "eles", proliferando inúmeros

6 Tradução livre realizada pelo autor: "uma mútua implicação de homogeneização e heterogeneização. Uma inclusão da localidade da diferença na mesma composição orgânica do global." 
ambientes forjadores de identidade cultural que, paradoxalmente, tendem a potencializar as diferenças culturais e aumentar os reclamos por diversidade. No mesmo instante em que a comunidade defende a homogeneidade cultural e proíbe o ingresso de qualquer coisa que Ihe seja estranha, alimenta os medos e as incertezas que inicialmente pretendia combater. Quanto maior a insegurança sentida pelos sujeitos de uma comunidade, menores são as chances de se estabelecer uma abertura para o diálogo com os outros diferentes, e mais fortes serão as medidas de segregação e divisão, restando prejudicada a conformação de uma comunidade "tecida em conjunto a partir do compartilhamento e do cuidado mútuo; de uma comunidade de interesse e responsabilidade em relação aos direitos iguais de sermos humanos e igual capacidade de agirmos em defesa desses direitos" (BAUMAN, 2003, p. 134).

Nenhum projeto que se elabore na sociedade contemporânea, comenta Bauman, consegue contar com a garantia de perenidade. Tudo se apresenta fugaz e efêmero. As afiliações sociais que tradicionalmente eram consideradas determinantes da identidade, como o Estado, a família, a religião, a raça e o gênero, revelam-se cada vez mais frágeis e, no seu lugar, novas formas de convívio social são projetadas como fontes de pertencimento que possibilitam a elaboração da identidade. É como se as identidades tradicionais mais sólidas e perenes, prossegue Bauman, não funcionassem nesse mundo de realidades líquidas; como se tivessem desaparecidos os grandes relatos unificadores, diria Lyotard (2004), eclodindo uma "sociedade transparente" (VATTIMO, 1990), na qual etnias, culturas, gênero, raças e comunidades apenas pudessem manifestar sua existência pela diferença de suas identidades.

Nessa trilha de argumentos, Hall (2005) destaca que a sociedade da modernidade tardia processa mudanças constantes, rápidas e provisórias, as quais têm contribuído para o descentramento, deslocamento e fragmentação das identidades modernas. Não apenas as localizações sociais tradicionais (família, gênero, religião, nacionalidade, raça) são enfraquecidas, mas o próprio "sentido de si" perde sua referenciabilidade nesse contexto, menciona Hall (2005). Assim, a identidade totalmente "unificada, completa, segura e coerente é 
uma fantasia". Em vez disso, prossegue o autor, os sujeitos se deparam com uma multiplicidade de sistemas de significação e representação cultural ao mesmo tempo, com os quais é possível se identificar, ao menos temporariamente. O processo de fragmentação das identidades produz uma espécie de subjetividade flexível, decorrente da vivência entrelaçada de diferentes culturas dentro de um mesmo indivíduo, que, na composição de sua vida, transita por uma diversidade de grupos sociais com práticas diferenciadas e até divergentes.

Na sociedade contemporânea e mesmo na modernidade, como já dissemos, o indivíduo convive ao mesmo tempo em vários espaços. Sua vida não é linear nem pré-ordenada. É complexa e, muitas vezes, caótica. Não mantém vínculos com um único sistema de sociabilidade. Não se pode, por isso, falar de um vínculo exclusivo com uma unidade, mas de vínculos com várias unidades a um só tempo. A própria história como algo unitário parece não ter mais sentido, disse Vattimo (2000, p. 29): "Vivir en este mundo múltiple significa experimentar la liberdad como oscilación contínua entre la permanencia y el extrañamento". Apoiandose em Heidegger e Nietzsche, o autor refere que o ser não coincide necessariamente com o estável, fixo e permanente; antes tem uma relação mais próxima com o evento, consenso, diálogo e interpretação, mas as experiências oscilantes do mundo contemporâneo podem servir como oportunidade de um novo modo de ser humano. O eu e o outro, portanto, encontram-se em uma fase dinâmica de suas constituições identificadoras.

A essência identitária desmoronou e, com isso, muitas identidades cambiantes e diversas convivem em um mesmo espaço e em espaços diferentes, produzindo estranhamento e reafirmando suas unidades. Se na sociedade pré-moderna os vínculos identitários eram fiéis a certa ordem de estabilidade, o que se vê no mundo moderno, e que foi potencializado no contemporâneo, é uma abertura do mundo para o indivíduo, que se coloca o dilema da unificação versus fragmentação.

Esse processo não retira a força da identidade, mas acaba com a ideia de uma identidade totalizante, de uma grande narrativa que dá 
conta de toda a experiência histórica do sujeito. No seu lugar, aparecem identidades múltiplas, confusas e móveis, advogando cada uma delas a sua diferença e apostando em seu estatuto de reconhecimento. Para cada demanda identitária é necessário apelar para estatutos de reconhecimentos diferentes.

Esse é o enredo atual da identidade: sujeitos atomizados buscando, cada um à sua maneira, afirmar sua diferença e ver reconhecida sua particular forma de estar no mundo.

\section{Conclusão}

O direito à identidade não surgiu como um direito de feições normativas específicas, como um direito subjetivo à identidade. Num primeiro momento, fez parte e foi conteúdo integrante dos direitos de proteção à vida, liberdade religiosa, integridade física, de pensamento, entre outros direitos que visam tutelar a autonomia e a liberdade individuais. Somente indiretamente se pode falar de um direito à identidade no início da modernidade.

Uma explicação bem elaborada do direito à identidade como um paradoxo é apresentada por Resta (1997). Segundo o professor italiano, ao tratar do problema da identidade, o sistema jurídico não pode fazer outra coisa além de interromper a inevitável complexidade, valendo-se de um "cliché normativo capace di non alterare tropo la esplosione di contingenze" (RESTA, 1997, p. 81) ${ }^{7}$. Ao regular a identidade, o direito necessita adotar um processo de generalização congruente. Define a identidade valendo-se de códigos específicos os quais conseguem generalizar uma convenção e um conceito abstrato que deverão orientar as expectativas e controlar a contingência. A normatividade reduz a complexidade jurídica da identidade ao definir seu teor de tutela e de proteção. Ao definir, separa, impede, seleciona algumas identidades

Tradução livre realizada pelo autor: "clichê normativo capaz de não alterar muito a explosão de contingência." 
entre tantas possibilidades existentes. Controla a própria contingência e a expectativa da identidade ao lhe dar um estatuto tipicamente jurídico que garante a previsibilidade de sua visibilidade pública.

A proteção jurídica de uma identidade se dá ao custo de se desproteger outras. Na verdade, não é a identidade que é defendida pelo direito, mas processos de identificação específicos que lhe interessam a ponto de se garantir um estatuto normativo próprio. Traços de identificação, e não de identidade em sua totalidade, é que são o alvo da norma. Por isso normas diferentes para diferentes tipos de identificação. Normas de proteção à liberdade sexual dos homossexuais, por exemplo, tratam de um específico ponto de identificação das pessoas com essa preferência sexual, mas não esgotam a identidade desses sujeitos, que é revelada também por outros traços de identificação (um gay pode ser negro, índio ou muçulmano, característica que nem sempre é considerada pela norma, pois se volta apenas à condição pontual da sexualidade).

O movimento de regular a identidade será sempre paradoxal, uma vez que a ambivalência e a contingência da identidade são reduzidas para serem controladas a partir de códigos que lhes são estranhos (mas normais ao sistema jurídico), os quais, para reconhecer normativamente a identidade, deverão atacar a complexidade que a constitui. Transformada em direito, em objeto de disputa e reconhecimento normativo, a identidade assume a linguagem autorreflexiva que caracteriza o sistema jurídico. Com o isso, o direito estabelece os limites de seu contorno, mas sempre a partir de seu exterior. Ele reconhece a diferença que interessa e a que não interessa, normatiza a identidade como um traço específico de pertença que estabelece um dentro e um fora, que inclui excluindo.

Ao internalizar a identidade a partir de sua linguagem específica, o direito só pode fazê-lo depurando e selecionando os conteúdos de modo codificado. A identidade, nesse sentido, é generalizada e estendida a todos como algo comum (RESTA, 1997). Sua proteção jurídica requer sua redução e uma espécie de estabilidade construída normativamente. Assim, o direito à identidade passa a ser aquilo que 
o direito diz e reconhece como tal. Na verdade, o direito à identidade diminui a própria autenticidade desta, transformando-se em recurso de proteção de traços normativos de identificação. A identidade é reduzida na linguagem jurídica a um modo de identificação. $O$ direito constitui-a normativamente, descaracterizando-a. Para ser tratada como um direito, ela perde doses significativas de sua existência como liberdade de ser. Como bem sintetiza Resta (1997, p. 92), a identidade "devono diventare in altra cosa per continuare ad essere identità".

Ao se ocupar de normatizar a identidade, o direito se propõe uma difícil tarefa, senão imprópria, pois desafia sua própria natureza generalista. O modelo moderno de direito centra-se numa lógica de imputação abstrata que lhe garante a sua generalização em condições de igualdade também abstrata. As normas jurídicas visam generalizar uma expectativa e reduzir a contingência. Nesse sentido, o direito, pela adoção de códigos específicos de comunicação, reduz a complexidade interna de seu sistema funcional e define os limites de seu entorno. Os conteúdos que fazem parte da programação do direito somente farão sentido dentro do sistema jurídico se capazes de serem lidos e assimilados pelo código binário lícito/ilícito. A substância normativa (a qual não se confunde com a substância da norma, pois o sistema jurídico é cognoscitivamente aberto e recebe influências de seu entorno no processo de programação) que interessa ao sistema jurídico é codificada pelo próprio sistema e de acordo com regras que ele mesmo estabelece (LUHMANN, 2000).

Apropriada pelo direito, a identidade reapresenta-se como algo artificial, uma unidade que generaliza e promete universalidade, mas não passa de uma convenção que invoca a diferença de sua comunidade. A identidade europeia é um exemplo disso. Segundo Resta (1997, p. 102), "nessnuna constituzione, nessun grande atto legislativo potrà dare identità all'Europa se non si vorrà investire razionalmente in un'istituzione

8 Tradução livre realizada pelo autor: "deve transformar-se em outra coisa para continuar a ser identidade." 


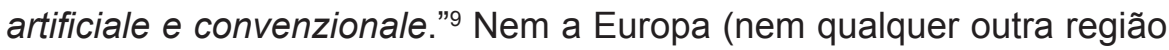
do mundo) apresenta uma unidade tão intensa que solape a capacidade individual de manifestação autêntica e agrupe a todos como se fosse uma comunidade sem diferenças. Definitivamente, somente como invenção e mito é possível defender a identidade com essas características.

A identidade transformada em direito é uma forma de produzir identificação a partir do exterior e reconhecer uma entre muitas possibilidades de o sujeito ser o que é. Nesse ponto, reside um grande problema para aliar o código do sistema jurídico ao código binário da identidade. Ambos operam binariamente. Porém, enquanto o direito faz uma espécie de generalização congruente, a identidade apoiase sempre e irrefutavelmente numa dinâmica contrária a todo tipo de generalização. Por isso, garantir o direito à identidade pela adoção do código lícito/ilícito significa negar a legitimidade das identidades não normatizadas ou, na direção contrária, em tons liberalizantes, permitir que todas as identidades façam o próprio caminho. Toda tentativa de regular a identidade normativamente é uma negação da sua condição autêntica e uma forma de negar as identidades não amparadas pela norma. Em palavras claras, o direito à identidade nos coloca diante do seguinte paradoxo: somos aquilo que somos, aquilo que nos identifica, mas nem sempre temos o direito de ser o que somos em virtude de que a vivência de nossa identidade, como direito, está subordinada à condição de normatividade.

Pode-se argumentar a favor de mecanismos jurídicos que protegem as formas de manifestação da identidade, de seu conteúdo, a sua identificação, mas não se pode interferir normativamente na definição dos conteúdos propriamente ditos. Isto é, o direito pode garantir um sistema de identificação, mas não pode garantir coercitivamente uma identidade. Identidade refere-se à possibilidade de se ser o que se é, independentemente de qualquer disposição normativa. O estatuto da

9 Tradução livre realizada pelo autor: "nenhuma Constituição, nenhum grande ato legislativo poderá dar identidade à Europa se não se investir racionalmente em uma instituição artificial e convencional." 
identidade tem relação próxima com o direito de liberdade de se ser o que se é. Não pode ser transfigurado em normatividade excludente que impõe, a partir do interior do sistema jurídico e, portanto, do exterior do sujeito, uma situação de exclusão normativa. Pois é isso que o direito à identidade acaba fazendo: reconhecer a identidade de alguém significa reconhecer as condições de liberdade de ser o que ele é, mas reconhecer um direito à identidade significa reconhecer um determinado traço de identificação definido a partir do externo, e não necessariamente pelo próprio indivíduo.

Ademais, como se sabe, a normatização da identidade não contempla todos os tipos de manifestações culturais, por considerar algumas delas contrárias ao direito. O discurso dos direitos humanos coloca sérias limitações às experiências culturais que negam a liberdade da pessoa e se amparam em elementos de violência, por exemplo. A universalidade de tais direitos se coloca na direção contrária às identidades que se alimentam da desigualdade e da opressão de todo tipo. Não se poderia falar de uma identidade como direito irrestrito de uma cultura fazer o que quiser com seus integrantes. Autorizar normativamente que certa cultura, uma identidade coletiva, obrigue seus membros a uma determinada experiência é também, e sobretudo, negar o direito individual de cada um viver sua vida a partir das próprias compreensões e visões de mundo, ou seja, de definir sua condição de ser, sua identidade. E o nó não se desata nunca. Ele é alimentado por um paradoxo interminável.

A identidade cultural homogeneíza as possibilidades de ação de seus integrantes, tolhendo em parte a sua autonomia, sua liberdade de serem e viverem como bem entenderem. Ao mesmo tempo, porém, garante-lhes uma pertença. A identidade, nesse caso, cessa quando cessa a pertença. Esse vínculo esgota-se no ato de pertencer, de fazer parte de uma comunidade. Sabemos, é claro, que nossa individualidade tem os seus limites e que sofre a constante influência do ambiente social onde vivemos. Por outro lado, podemos fazer escolhas, reinventar nosso passado, movimentar-nos em direção ao novo e a novas possibilidades de vida. $O$ direito à identidade individual, portanto, pode nos colocar 
em conflito com a identidade cultural do grupo de que fazemos parte. E o direito não apresenta uma solução para esse impasse que ele mesmo cria. Se a identidade de tipo cultural acaba quando acaba o jogo da pertença, a identidade individual, no entanto, segue seu curso, reinventa-se, faz novos contatos e redefine os próprios limites.

O direito à identidade, em seu sentido amplo, só poderia assentarse no direito à liberdade. Direito à identidade de tipo estratificado (que corretamente deveria ser chamado de direito à identificação) alimenta um jogo interminável de identidades que se rivalizam e se negam, cada uma delas reproduzindo o próprio estatuto. Todo tipo de legislação que reconhece apenas alguns traços da individualidade humana e os protege está, em verdade, protegendo processos de identificação. É um processo externo, que faz a leitura e as significações das formas como a identidade se manifesta e se representa, individual e coletivamente. A identidade como direito de ser o que se é não se confunde com as possíveis representações que dela são feitas. O sistema jurídico não consegue universalizar o direito à identidade porque adota uma forma de generalização congruente, que seleciona determinadas identificações em detrimento de outras. Ao fazer isso, ao negar seu entorno, o direito à identidade nega aquilo que com ele não se assemelha. $O$ direito de ter uma identidade estará sempre em contraposição a uma identidade diferente. Por isso dizemos que a melhor forma de garantir o livre fluxo das identidades só pode estar associada ao reconhecimento de uma racionalidade jurídica de tipo não standartizador e sectário, que seja capaz de apostar na humanidade comum do homem como modelo universal de direitos humanos.

\section{Referências}

BAUMAN, Zygmunt. Comunidade: a busca por segurança no mundo atual. Tradução de Plínio Dentzein. Rio de Janeiro: Zahar, 2003.

BAUMAN, Zygmunt. De Peregrino a turista, o uma breve historia de la indetidad. In: HALL, Stuart; GAY, Paul du. (Comp.). Cuestiones de identidad cultural. Buenos Aires: Amorrortu, 2003. p. 40-68. 
BAUMAN, Zygmunt. Identidade. Tradução de Carlos Alberto Medeiros. Rio de Janeiro: Zahar, 2005. Entrevista concedida a Benedetto Vecchi. BAYART, Jean-François. L'illusion identitaire. Paris: Fayard, 1996.

BAUMAN, Zygmunt. A sociedade individualizada: vidas contadas e histórias vividas. Tradução de José Gradel. Rio de Janeiro: Zahar, 2010.

BENHABIB, Seyla. Los derechos de los otros. Extranjeros, residentes y ciudadanos. Barcelona: Gedisa, 2005.

BREUILLY, John. Nacionalismo y Estado. Traducción de José Pomares. Barcelona: Pomares-Corredor, 1990.

BRONOWOSKI, Jacob. L'identità dell'uomo. Milano: Edizione di Comunità, 1968.

BURKE, Peter. Hibridismo cultural. Tradução de Leila Souza Mendes. São Leopoldo: Unisinos, 2006.

DOUZINAS, Costas. O fim dos direitos humanos. São Leopoldo: Unisinos, 2009.

DUBAR, Claude. La crise des identités. 3. ed. Paris: PUF, 2007.

ELIAS, Norbert. A sociedade dos indivíduos. Tradução de Vera Ribeiro. Rio de Janeiro: Zahar, 1994.

FEATHERSTONE, Mike. Trasformazioni. corpo, imagine ed affect nella cultura dei consumi. In: GUIZZARDI, Gustavo. Identità incorporate: segni, immagini, differenze. Bologna: Mulino, 2009. p. 102-132.

FERRY, Luc. Famílias, amo vocês: política e vida privada na era da globalização. Tradução de Jorge Bastos. Rio de Janeiro: Objetiva, 2010.

FRAILLE, Guillermo. Historia de la filosofía I. Madrid: Editorial Catolica, 1961.

GADAMER, Hans-Georg. Linguaggio. Tradução de Donatella di Cesare. Roma-Bari: Laterza, 2005.

GALIMBERTI, Umberto. II corpo. 20. ed. Milano: Feltrinelli, 2010. 
GALIMBERTI, Umberto. I miti del nostro tempo. Milano: Feltrineli, 2009.

GELLNER, Ernest. Naciones y nacionalismo. Madrid: Alianza, 1988.

GIDDENS, Anthony. As consequências da modernidade. Tradução de Raul Fiker. São Paulo: Unesp, 1991.

GIDDENS, Anthony. Modernidade e identidade. Tradução de Plínio Dentzien. Rio de Janeiro: Zahar, 2002.

GRONDIN, Jean. Introdução à hermenêutica filosófica. Tradução e apresentação de Benno Dischinger. São Leopoldo: Unisinos, 1999.

HABERMAS, Jürgen. Direito e democracia. Rio de Janeiro: Tempo Brasileiro, 1997. v. II.

HABERMAS, Jürgen. Inclusão: integrar ou incorporar? Sobre a relação entre nação, estado de direito e democracia. Revista Novos Estudos Cebrap, São Paulo, n. 52, p. 102-121, 1998.

HABERMAS, Jürgen. A inclusão do outro: estudos de teoria política. Tradução de George Sperber e Paulo Astor Soethe. São Paulo: Loyola, 2002.

HALL, Stuart. A identidade cultural na pós-modernidade. Tradução de Tomaz Tadeu da Silva e Guacira Lopes Louro. 10. ed. Rio de Janeiro: DP\&A, 2005.

HALL, Stuart. Introducción? ¿Quién necesita de "identitad"? In: HALL, Stuart; GAY, Paul du. (Comp.). Cuestiones de identidad cultural. Buenos Aires: Amorrortu, 2003. p. 13-39.

HEGEL, Friedrich G. W. Enciclopédia das ciências filosóficas em compêndio. Tradução de Paulo Meneses. São Paulo: Loyola, 1995. v. I.

HEIDEGGER, Martin. Identidad y diferencia = Identität und differenzi. Edición bilíngüe. Barcelona: Anthropos, 1990.

HEIDEGGER, Martin. Ser e tempo. 12. ed. Petrópolis: Vozes, 2002. v. I. HIRSCHBERGER, Johannes. Historia de la filosofía I. Barcelona: Herder, 1954. 
HÖFFE, Otfried. Aristóteles. Porto Alegre: Artmed, 2008.

HUME, David. Tratado da Natureza Humana. Tradução de Débora Danowski. São Paulo: Unesp, 2002.

KYMLICKA, Will; STRAEHLE, Christine. Cosmopolitismo, Estadonación y nacionalismo: un análisis crítico de la literatura reciente. México: Universidad Nacional Autónoma de México, 2001.

LAGO, Emanuele. Identità e differenza: Heidegger, Hegel e l'altro inizio del pensiero. 2008. Tese (Doutorado)-Scuola di dottorato di ricerca in Filosofia, Università degli Studi di Padova, 2008.

LOCKE, John. Ensaios acerca do entendimento humano. Tradução de Anoar Aiex. São Paulo: Nova Cultural, 2000.

LUCAS, Doglas Cesar. Direitos humanos e interculturalidade: um diálogo entre a igualdade e a diferença. ljuí: Unijuí, 2010.

LUHMANN, Niklas. El derecho de la sociedad. Madri: Iberoamericana, 2000.

LYOTARD, Jean-François. La condición postmoderna: informe sobre el saber. Traducción de Mariano Antolín Rato. 8. ed. Cátedra: Madrid, 2004.

MAFFESOLI, Michel. Identidad e identifición en las sociedades contemporáneas. In: ARDITI, Benjamin. El reverso da diferença: identidad y política. Caracas: Nueva Sociedad, 2000. p. 7-14.

MARRAMAO, Giacomo. II mondo e l'occidente oggi: il problema di una sfera globale. [S.I.; s.n.], 2007. Mimeografado.

MARRAMAO, Giacomo. Passagio a Ocidente: Filosofia e globalizzazione. Torino: Bollati Boringhieri, 2003.

MENDÉZ, Manuel Toscano. Nacionalismo y pluralismo cultural: algunas consideraciones. In: CARRACEDO, José Rubio et al. Ciudadanía, nacionalismo y derechos humanos. Madrid: Trotta, 2000. p. 47-72.

REMOTTI, Francesco. Contro l'identità. 4. ed. Roma: Laterza, 2007. 
REMOTTI, Francesco. L'ossessione identitaria. Roma: Laterza, 2010. RESTA, Eligio. Diritto fraterno. Roma: Laterza, 2008.

RESTA, Eligio. Diritto vivente. Roma: Laterza, 2008.

RESTA, Eligio. L'estelle e le masserizie: paradigmi dell'osservatore. Roma: Laterza, 1997.

RESTA, Eligio. L'identità nel corpo. In: RODOTÀ, Stefano; ZATTI Paolo. Il governo del corpo. Milano: Giuffrè, 2011. p. 3-27.

RICOEUR, Paul. Percurso do reconhecimento. Tradução de Nicolás Nyimi Campanário. São Paulo: Loyola, 2006.

RUIZ, Castor M. M. Bartolomé. O (ab)uso da tolerância na produção de subjetividades flexíveis. In: SIDEKUM, Antônio (Org.). Alteridade e multiculturalismo. Ijuí: Unijuí, 2003. p. 115-171.

TIVEY, Leonard. El Estado nación. Tradução de Marco-Aurelio Galmarini. Barcelona: Península, 1987.

ATTIMO, Gianni. Posmoderno. ¿Una sociedad transparente? In: ARDITI, Benjamin. El reverso da diferença: identidad y política. Caracas: Nueva Sociedad, 2000. p. 15-22.

VATTIMO, Gianni. La sociedad transparente. Barcelona: Paidós, 1990. WATANABE, Lygia. Platão por mitos e hipótesis. São Paulo: Moderna, 1995.

Recebido em: 19/09/13

Aprovado em: 23/11/13 